\title{
Catalysing pedagogical change in the university ecosystem: Exploring 'big ideas' that drive faculty development
}

\author{
HELGA DORNER $^{1 *}$ (1) and KATARINA MÅRTENSSON ${ }^{2}$ \\ ${ }^{1}$ Eötvös Loránd University, Budapest, Hungary \\ ${ }^{2}$ Lund University, Lund, Sweden
}

\section{EDITORIAL}

(C) 2021 The Author(s)

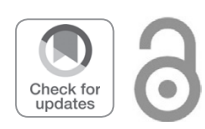

Improving teaching has continuously been on the agenda worldwide over the past decades (cf. European Commission, 2017; Schumann, Peters, \& Olsen, 2013), particularly in a constantly changing higher education climate where new trends cross institutional and national borders. Programs that aim to enhance the quality of teaching and the student learning experience have gradually become a common feature, sometimes even a requirement, of many higher education institutions. In certain geographical areas however, for example Central and Eastern Europe, such development work has only recently begun. Nevertheless, particularly in the post-COVID era, the need for sustainable faculty development initiatives has gained wide recognition and, to a growing extent, become unquestionable. This special issue of the Hungarian Educational Research Journal is therefore a crucial endeavour to situate the international scholarly dialogue about faculty development - also known as educational or academic development - in an intellectual space that has not yet extensively engaged with faculty development practices nor with research on it.

Leibowitz (2014) argues that "the way we use the phrase 'academic development', or the terrain in which we use it, shifts over time and across geographical locations", and given this, it is about "the creation of conditions supportive of teaching and learning, in the broadest sense" (p. 359). Known from international institutional practices and reputable scholarly work, academic development units are hence charged with supporting faculty in enhancing their teaching and mentoring, and acting as catalysts for pedagogical change. As Gibbs (2013) remarks, this increasingly complex mission implies diverse theoretical grounding and approaches to faculty development. Over time, Gibbs argues, the academic development practice has moved from advising and consulting individual faculty on their teaching practices to increasingly also focus

*Corresponding author. E-mail: dorner.helga@ppk.elte.hu 
on curricular innovation, support for teaching teams and departments, as well as working strategically within institutions at policy- and management levels. Likewise, Sutherland (2018) speaks about 'holistic academic development' and reflects on this complexity by highlighting three equally relevant areas of development work that are the whole of the academic role, the whole institution, and the whole person. The "academic development project" (Clegg, 2009) has thus undergone a major expansion of activities; as Stensaker, Bilbow, Breslow, and van der Vaart (2017) argue, it is linked to institutional strategies and embedded in the structural and organizational context of teaching and learning, which inevitably also falls under the umbrella of university administration and management. Academic developers are therefore expected to embark on a pedagogical endeavour to also enhance the human resources of the institution, in particular, through professionalizing academic practice and capacity building for leadership (Stensaker et al., 2017, pp. 21-23).

Accordingly, the conceptual grounding for this special issue is this understanding that academic and development work both take place in a complex ecosystem (Hannah \& Lester, 2009; Roxå, 2014) where members interact with each other and the surrounding environment (in the institutional or organizational sense), and intentionally create synergies at the different levels of organizational complexity of the university. These levels of complexity within an (academic) organization are conceptualized as micro-, meso-, and macro-levels where micro refers to the individual (academic) and their development readiness, meso encompasses the networks such as workgroups, collaborations, teaching and research teams, departments, and macro entails the overarching systems of networks that are, for instance, faculty, institution or society at large (the latter sometimes referred to as the mega-level) (Hannah \& Lester, 2009; Mårtensson, 2014; Roxå \& Mårtensson, 2012; Simmons, 2020).

This multi-level approach to understanding academic development and organizational learning in the university-context is also reflected in the overarching aim and structure of the special issue. As editors and authors, we aspired to critically engage with development work by taking the multi-level perspective and reflecting on the 'big ideas' and fundamental conceptualizations behind approaches, practices, and paths pursued by academic developers in the changing international landscape of higher education.

A macro-perspective is taken by Johan Geertsema, based in Singapore, who situates faculty development in the larger academic context. In so doing, his thinking transcends institutional boundaries and provides a thoughtful frame for development approaches and practices which are discussed in the articles to follow in the special issue. A point of departure (that is shared, in fact, by all authors) is certainly the importance of institutional context so as to create meaningful opportunities to enact faculty development. In other words, the complexities that are pertinent to a certain context in the realm of the institution must be taken into consideration. Geertsema thus acknowledges that academic developers have their agency but need to take into account the structures in which they enact academic development, and he wisely concludes that "[i]t is this interplay of 'structure' and 'agency' that is in part what renders change processes and academic development so difficult" (2021, p. 231). However, structure is also thought of as a much broader entity than the institutional setting itself; faculty development is thus understood as the complex practice of dealing with change, which may be caused by circumstances that are beyond faculty developers and their units (such as dynamics created by the COVID-19 crisis in higher education). Geertsema accordingly provides a thoughtful analysis of why 'big ideas' or theories of change are needed to ensure a holistic as well as a nuanced understanding of change that sets the 
ground for faculty development practices which interact with the wider surrounding but also are sensitive to the meso- and micro-layers, such as academic identities, disciplinarity, or microcultures in academe (cf. Mårtensson, 2014). His critical reflection on institutional practices and (leadership) decisions clearly underpins the message that having or developing a "strategic approach to academic development as culture change" (Geertsema, 2021, p. 236) is fundamental to all of us working on a framework for effecting change in higher education within and beyond our institutional boundaries.

A possible entry point to culture change within an institution, that is, the meso-level of the university ecosystem may be academic development targeting doctoral students. As Gorana Misic, Margaryta Rymarenko, and Helga Dorner, based in Hungary, explain, doctoral students in training are a non-traditional audience for academic development, as such programs usually focus on faculty at different career stages. Hence, launching a program for doctoral students embodies the first step towards an intentional strategy to engage in the enhancement of teaching and learning in an institutional environment that had previously lacked academic development initiatives. Being intentional about such development work also necessitates a program theory or a set of core pedagogical principles which underpin activities, and are meaningful in the particular institutional context as well as embraced at the meso- and micro-levels. Misic, Rymarenko, and Dorner thus provide a synthesis of the theoretical grounding of their program by also offering insights on its operationalization. Although concerned with theoretical underpinnings, the paper nevertheless directs our attention to conceptualizing doctoral students as change agents within an organization who, through horizontal collaborations with academic developers and other academics, may catalyse and diffuse pedagogical change in the campus ecosystem (Hannah \& Lester, 2009; Roxå, 2014) at the micro- and meso-levels.

The idea of strategic academic development that is grounded in a theory (or theories) of change and aimed at holistic development work (Sutherland, 2018) is also embraced by Rie Troelsen, based in Denmark. Her analysis nevertheless drills down into the meso-level of development work and explores how faculty development with its expanded set of activities may contribute to organizational change in a particular institutional context. Overarching faculty development strategies are shared, through which expertise and leadership residing in academic development units may be leveraged for organizational learning. In so doing, Troelsen describes and critically engages with the strategic leadership Teaching and Learning Centre maturity framework developed by Holt, Palmer, and Challis (2011). Through the example of her own meso-context, the case of a Danish Center for Teaching and Learning, Troelsen shares a unique insight into a center director's strategic thinking on how best to align academic development practices to the "complex activity systems" of the university (Saroyan, 2014, p. 63), which also resonates with Geertsema's (2021) analysis. At the same time however, Troelsen invites us to think through those (current and future development) activities which reinforce the importance of strategic partnership among academic developers, university leadership and academics. Such intentionally created synergies, as we see, are conceived of as prerequisites of sustainable operations of academic development units that are inevitable to endure regular reconfiguration in the ever changing higher education scene.

Productive and mutually beneficial synergies among academic developers, academics and academic leadership are discussed by Deandra Little and Jessie Moore, based in the USA, who engage in the analysis of the micro-level complexities of development work. Their analysis builds on extended case studies or a typology of faculty who have become active in the scholarship of teaching and learning (SoTL) and departed on personalized pathways through academic 
development activities. Being sensitive to and intentional about the different levels within the campus ecosystem (Hannah \& Lester, 2009; Roxå, 2014) as well as the different career stages of academics are crucial strategies to providing growth opportunities for faculty. Therefore, Little and Moore encourage those of us involved in academic development to plan and offer a variety of development options with a flexibility of time commitment and personal-professional interests to faculty. At the micro-level this approach thus embraces development readiness and creates individual ownership and sustainable engagement. Importantly however, their analysis too underscores the cross-fertilization potential of this intentionality, in as much as through the in-built flexibility of multiple pathways for engagement, faculty may share experiences, practices and approaches at various levels of the ecosystem. In other words, they may become change agents or catalysts of change by linking the various stakeholders of the multi-level structure through their development activities and achievements. In this understanding, resonating with Misic, Rymarenko, and Dorner new ideas or practices may trickle down from macro-level activities but pedagogical innovations at the meso and micro levels may also generate change at the macro level, for instance, become point-of-reference for policy-making or leadership-decisions.

Undoubtedly, trade-offs are part of these cross-fertilization dynamics, as Lise Toft Henriksen and Lea Stoer Eskesen, based in Norway, highlight in their paper. The inevitable boundary crossing that comes with the expanded academic development activities oriented towards the institutional rather than the individual (Gibbs, 2013) points to the debate, also elaborated by Geertsema, whether academic development is indeed academic work or conceptualized more as an administrative task. Hence, implementing and contributing to institutional policies and university strategies may often challenge development work and practices traditionally built on mutual trust, formative and voluntary participation, and on respecting the needs of those involved. Toft Henriksen and Stor Eskesen generously offer an insight into the micro-level dynamics of their faculty development where participants hold contradictory perspectives on the activities performed. In particular, program evaluation, an activity certainly associated with university leadership and strategies, is enacted by the academic development unit which has not been previously involved in summative evaluations or assessment practices. Mindful of the unintended changes in collegial and productive relationships between academic developers and academics, Toft Henriksen and Stoer Eskesen draw our attention to how such activities, if not preceded by strategic planning and considerations, may compromise development work and pose challenges to brokering pedagogical knowledge to various levels of the ecosystem. Negotiation and renegotiation of change within institutions and beyond, as Land (2004) puts it, therefore often means considering the trade-offs and their implications, which may challenge the sustainable operation of academic development units and therefore push them to a state in constant flux.

It is our hope and ambition with this special issue that academic developers and academic development units can use these 'big ideas' and lessons learnt as a way to navigate the state of constant flux, and find sustainable ways forward, particularly if it is a fairly new endeavour.

\section{REFERENCES}

Clegg, S. (2009). Forms of knowing and academic development practice. Studies in Higher Education, 34(4), 403-416. https://doi.org/10.1080/03075070902771937. 
European Commission/EACEA/Eurydice (2017). Modernisation of higher education in Europe: Academic Staff - 2017. Eurydice report. Luxembourg: Publications Office of the European Union.

Geertsema, J. (2021). Faculty development in the context of a research-intensive university. Hungarian Educational Research Journal, 2021(3), 230-245.

Gibbs, G. (2013). Reflections on the changing nature of educational development. International Journal for Academic Development, 18(1), 4-14. https://doi.org/10.1080/1360144X.2013.751691.

Hannah, S. T., \& Lester, P. B. (2009). A multilevel approach to building and leading learning organizations. The Leadership Quarterly, 20: 34-48.

Holt, D., Palmer, S., \& Challis, D. (2011). Changing perspectives: Teaching and learning centres' strategic contributions to academic development in Australian higher education. International Journal for Academic Development, 16(1), 5-17.

Land, R. (2004). Educational development: Discourse, identity and practice. Buckingham: Society for Research into Higher Education and Open University Press.

Leibowitz, B. (2014). Reflections on academic development: What is in a name? International Journal for Academic Development, 19(4), 357-360. http://dx.doi.org/10.1080/1360144X.2014.969978.

Mårtensson, K. (2014). Influencing teaching and learning microcultures. Academic development in a research-intensive university. Lund University (Media-Tryck).

Roxå, T. (2014). Microcultures in the meso level of higher education organisations: The commons, the club, the market, and the square. Doctoral dissertation.

Roxå, T., \& Mårtensson, K. (2012). How effects from teacher training of academic teachers propagate into the meso level and beyond. In E. Simon \& G. Pleschova (Eds.), Teacher development in higher education. Existing programs, program impact, and future trend (pp. 213-233). London, UK: Routledge.

Saroyan, A. (2014). Agency matters: academic developers' quests and achievements. International Journal for Academic Development, 19(1), 57-64.

Schumann, D. W., Peters, J., \& Olsen, T. (2013). Cocreating value in teaching and learning centers. New Directions for Teaching and Learning, 21-32. https://doi.org/10.1002/tl.20043.

Simmons, N. (2020). The 4M framework as analytic lens for SoTL's impact: A study of seven scholars. Teaching \& Learning Inquiry, 8(1). http://dx.doi.org/10.20343/teachlearninqu.8.1.6.

Stensaker, B., Bilbow, G. T., Breslow, L., \& van der Vaart, R. (2017). Strategic challenges in the development of teaching and learning in research-intensive universities. In B. Stensaker, G. T. Bilbow, L. Breslow, \& R. van der Vaart (Eds.), Strengthening teaching and learning in research universities (pp. 1-18). Palgrave Macmillan.

Sutherland, K. A. (2018). Holistic academic development: Is it time to think more broadly about the academic development project? International Journal for Academic Development, 23(4), 261-273. https:// doi.org/10.1080/1360144X.2018.1524571.

Open Access. This is an open-access article distributed under the terms of the Creative Commons Attribution-NonCommercial 4.0 International License (https://creativecommons.org/licenses/by-nc/4.0/), which permits unrestricted use, distribution, and reproduction in any medium for non-commercial purposes, provided the original author and source are credited, a link to the CC License is provided, and changes - if any - are indicated. 